\title{
The formation of self-efficacy beliefs of skilled professional employees in a South African fruit export organisation
}

\author{
W. Anyster \\ Simply Talented International \\ S. Goodman* \\ Section of Organisational Psychology, School of Management Studies, \\ University of Cape Town, Republic of South Africa \\ sgoodman@commerce.uct.ac.za \\ T. Wallis \\ The WorkLife Centre
}

Received January 2006

\begin{abstract}
This research explores the formation of self-efficacy beliefs from the perspective of individual employees occupying formal work roles within the supply chain division of an international fruit-marketing organisation. Bandura's (1977; 1986; 1997) Social Cognitive Theory and research contributions on the formation of self-efficacy beliefs define the context in which this research is located. Qualitative data was obtained through in-depth interviews with fifteen subjects with more than two years work experience. Results indicate that employees derive efficacy information primarily through performance accomplishments, persuasive feedback from significant others and social comparative information. Specifically successful performance experiences appear to enhance perceptions of self-efficacy more than information derived from any other source.
\end{abstract}

*To whom all correspondence should be addressed.

\section{Introduction}

Self-efficacy beliefs, the perceptions that people have about their capabilities, powerfully influence their work-related behaviour and performance (Bandura, 1997). As a result, individual competencies and past performance records are not necessarily good predictors of future performance, since self-efficacy beliefs are instrumental in determining what individuals do with the knowledge and skills they have (Maehr \& Pintrich, 2000; Pajares, 2000).

While there is consensus that self-efficacy is important for individual performance at work and ultimately business success, there is limited research about the sources on which people base their self-efficacy appraisals. Quantitative research in this area (e.g. Bandura, 1997; Cervone, 2000; Early \& Gibson, 1999; Stadjkovic \& Luthans, 1998) has thus far failed to explain the complex processes involved in the formation of these beliefs.

The aim of this study was to contribute a deeper understanding of the information referents in the work environment used in developing self-efficacy beliefs. It aims to generate a model of these information referents which can be applied and tested in further empirical studies.

A qualitative research design was chosen to elicit the dynamic process underlying the formation of efficacy judgements. Emphasis was placed on gaining insight into this phenomenon from the individual's personal experiences. The qualitative approach of the study provided insight into the complexities influencing the choice of information referents in the formation of efficacy beliefs.

\section{Overview of the information sources of self-efficacy}

According to Bandura (1997) and Pajares (2000), selfefficacy beliefs are derived from four principle sources of information: enactive mastery (performance accomplishments), vicarious experiences (modelled exposure), verbal persuasion and physiological arousal or affective states. However, Early and Gibson (1999) have argued that the origins of efficacy judgements are not clear, and that the sources may be more varied and complex than implied by the four categories of information sources. Gist (1987) proposed that, while these four sources provide important information cues, it is the cognitive appraisal and integration of data from the information sources that ultimately determines self-efficacy. Perceptions of selfefficacy are more strongly influenced by the subjective perceptions of personal and situational factors, rather than the direct impact of objective reality (Stadjkovic \& Luthans, 1998). 


\section{Information cues in self-efficacy formation}

Judgements about self-efficacy become more routinised and automatic as experience with a task increases (Gist \& Mitchell, 1992). This is because accumulated personal experiences of task performance provide direct knowledge about capabilities. When tasks are novel or unfamiliar, however, the individual may use data from social modelling, verbal persuasion and arousal, which are less direct and would require a more detailed analysis of the task demands, the environmental constraints and the individual's own personal factors. Forming efficacy judgements may therefore involve extensive analysis of task requirements and/or the recollection of past performance levels (Gist \& Mitchell, 1992).

Social and situational moderator effects influence the efficacy indicators that people will attend to and the information base upon which the self-appraisal process operates (Bandura, 1997), therefore both individual and situational factors need to be considered when exploring the formation of efficacy beliefs (Cervone, 2000). Examples of these factors are conceptions of ability, perceived controllability, information or assumptions that link successful performance to internal or external factors, and feedback received regarding previous performance (Appelbaum, 1996; Bandura, 1988).

Research results indicate that self-efficacy judgements are dynamically influenced by externally provided information (Appelbaum, 1996; Pajares, 2000). Factors in the organisational context that may influence the selection of information referents include the accessibility of the source, credibility of the feedback giver and the possible affective sign of the information (Sully De Luque, 2000). Other external factors also influencing self-efficacy judgements include task complexity (the steps required to perform the task successfully), task uncertainty (the dynamic elements of a task) and the actual environment in which the task is performed (Appelbaum, 1996).

\section{Implications of self-efficacy for organisational behaviour}

Several studies have reported a significant relationship between self-efficacy and work-related performance (Bandura, 1997; Brief \& Aldag, 2001; Cervone, 2000; Wood \& Bandura, 1989). Research has demonstrated that self-efficacy beliefs affect performance attainments by influencing effort, persistence and perseverance in task attainment (Pajares, 2000).

Self-efficacy beliefs play a central role in the self-regulation of motivation (Bandura, 1999). Studies by Bandura (1991) and Locke and Latham (1990) produced similar findings of the impact of perceived self-efficacy on goal aspirations. It is partly on the basis of self-efficacy that people choose which goals to pursue, the amount of effort to invest in pursuing the goal and how long to persevere in the face of difficulties and obstacles (Locke \& Latham, 1990). When faced with obstacles, setbacks and failures, those who have conviction in their capabilities to succeed redouble their efforts, while those who doubt their capabilities slacken their efforts, give up or settle for mediocre solutions (Bandura, 1991). The stronger an individual's perceived self-efficacy, the higher the goal aspirations people adopt, and the firmer their commitment to the goals will be (Bandura, 1991; Locke \& Latham, 1990).

Previous research findings have found self-efficacy to be a better predictor of future performance than past behaviour (Gist, 1987), as long as the efficacy measure is tailored to the specific tasks being assessed (Bandura (1982), as cited in Gist (1987)). Self-efficacy theory also provides new insights into self-esteem/job performance relationships, organisational socialisation processes and stress/job performance relationships (Brief \& Aldag, 2001). This does not mean that people can accomplish tasks beyond their capabilities by simply having the personal belief that they can. Rather, it means that for competent functioning or performance there must be a congruency between skills and knowledge on the one hand and personal beliefs of efficacy on the other hand (Pajares, 2000).

Research conducted within the South African life assurance industry found that supervisory support moderated the relationship between self-efficacy and supervisor-rated performance (Ballantine \& Nunns, 1998). Employee performance was highest when low levels of self-efficacy occurred together with high supervisory support as supervisory support enhanced an individual's confidence to set more difficult goals, resulting in higher levels of performance. While supervisory support enhanced the performance of individuals with low efficacy, the study showed that it inhibited the performance of individuals with high efficacy (Ballantine \& Nunns, 1998). Findings suggested that individuals with high efficacy possibly require less supervisory support precisely because of their self-efficacy (Ballantine \& Nunns, 1998).

Despite the impressive empirical support for the relationship between self-efficacy and work performance, the field of human resource management has paid little attention to the organisational applications of self-efficacy (Appelbaum, 1996; Gist, 1987). Human resource management practices in the area of work motivation and performance have reflected the application of goal setting theory and rewards in order to enhance motivation and performance, but seem to overlook the influence of an individual's evaluation of his or her task competence, that is, perceived self-efficacy.

In addition, several limitations of previous empirical research on self efficacy in general identified by Harrison and Rainer (1997) are noted. Firstly, most of the empirical research on the concept in general was performed in a laboratory; secondly, many samples consisted exclusively of students as opposed to employees in organisational settings; and, thirdly, the majority of the research was performed with tasks that did not relate to organisational performance. Harrison and Rainer (1997) therefore argued that, as a consequence, many findings are not generalisable to actual performance, whilst Gist (1987, as cited in Harrison \& Rainer, 1997) stressed the need for more detailed examinations of self-efficacy and its linkages to performance in organisational settings. 
While significant relationships between self-efficacy and motivation variables such as effort, persistence and perseverance have been established, Pajares (2000) has also argued that it is still not clear how these connections are made or under what conditions similar beliefs can result in different levels of motivation. Researchers (e.g. Maehr \& Pintrich, 2000) have therefore emphasised that quantitative efforts will have to be complemented by qualitative studies aimed at exploring how efficacy beliefs are developed and how individuals perceive their self-efficacy beliefs to influence their attainments, career paths, choices, effort, persistence, perseverance and resiliency. As a result of such calls, the current research employed qualitative methodologies to explore the origins of self-efficacy beliefs in an organisational setting and attempted to develop a model that explains these sources.

\section{Method}

The purpose of the present study was to deepen the understanding of the formation of self-efficacy beliefs within a work context. As personal meaning is tied to context (Maykut \& Morehouse, 1994), qualitative research was chosen for the study as it provides rich and holistic data, revealing complexity and yielding 'thick' descriptions that are vivid and contextual (Miles \& Huberman, 1994). Given the relationship between self efficacy and performance, extending the understanding of the formation of these beliefs will enable supervisors and managers to influence self efficacy beliefs so as to influence organisational behaviours.

The unit of analysis in this study was the individual within the case. The bounded context in this research was a division of an international fruit-marketing organisation responsible for the management of the supply chain. A total of sixty highly skilled, professional staff are employed in this division. The final sample consisted of fifteen skilled, professional (graduates or diplomates) employees with more than two years work experience, currently employed in the supply chain division.

The principal researcher deliberately selected the study participants in order to create a contrast in the sample in terms of age, gender, education and occupation.

\section{Data collection}

The data of qualitative inquiry is most often people's words and actions, and this requires methods that enable the researcher to capture language and behaviour (Maykut \& Morehouse, 1994). Data was therefore collected through indepth interviews (Kvale, 1983). The interviewer (the principal researcher) spent a minimum of one hour with each participant in order to gain meaningful insight into their personal experiences related to the formation of their self-efficacy beliefs.

The questions were designed to help participants to uncover beliefs that had been submerged beneath the surface of the consciousness. The interview questions were informed by the four sources of self-efficacy beliefs postulated by Bandura (1997), namely: enactive mastery experiences; vicarious experiences; verbal or social persuasion and psychological arousal. A number of open-ended questions were also posed to elicit information about the potential impact of information sources not identified by Bandura (1997) and to explore the potential impact of environmental factors on the choice of information referents.

The interviewer took care to cover all the questions in more or less the same order for each participant, in this way somewhat prescribing the conversational context of each interview (McCracken, 1988). However, depending on the responses to the questions posed, the order of the questions varied in each interview. Some interviewees had difficulty answering those questions that attempted to directly elicit beliefs that they have about their own capabilities. When this happened, the interviewer went on to another question then came back to the previous question later in the interview and/or posed the question differently. The interviewer also probed for specific examples or clarification in order to obtain rich insight and understanding of the view being expressed by each subject. Clarification and confirmation were also obtained periodically throughout the interview by the use of reflective summaries (Schamberger, 1997), which also gave the interviewer the opportunity to steer the discussion around desired themes. Silences were also tolerated as these pauses for thought gave the subject time to add information. The interviewer also listened for other things like impression management, topic avoidance, minor misunderstanding and outright miscomprehension, taking in each case the necessary remedy to deal with the problem. For example, when the interviewee deliberately avoided a question, the interviewer tried to approach the topic in a less threatening way.

While the questions brought structure and order into the qualitative interview, it did not detract from the open-ended nature of this methodology. Within each of the questions, the opportunity for unstructured and exploratory responses remained. This opportunity is in fact essential to allow variability within the interview (McCracken, 1988).

Each taped interview was transcribed to produce a hard copy transcript recording each word during the interview. These transcripts provided the basis for analysis of the data.

\section{Data analysis and interpretation}

The approach to data analysis in the present study can be termed interpretative-descriptive (Belenky, 1992, as cited in Maykut \& Morehouse, 1994). The researchers were primarily concerned with accurately describing what they had understood, and then reconstructing the data into a 'recognisable reality' for the people who had participated in the study (Maykut \& Morehouse, 1994). This approach therefore required some selection and interpretation of the data by the researchers.

The interpretative-descriptive approach was highly relevant for the present study as research findings are described and interpreted within the framework of the existing theory with a view to offering insight for organisations and individuals into the formation of self-efficacy beliefs. 


\section{Results and discussion}

Figure 1 is a graphic representation of the results of the study. The various components of the model are discussed in this section.

\section{Performance accomplishments}

As in previous research (Bandura, 1988, 1997; Gist, 1987; Wood \& Bandura, 1989), participants' experiences related to task performance emerged as the primary information source in the formation of their self-efficacy beliefs. The specific positive or negative impact of such experiences on self-efficacy beliefs was dependent on each individual's evaluation of the influence of the following personal and situational factors (Bandura, 1997; Cervone, 2000; Stadjkovik \& Luthans, 1998).

\section{Conceptions of ability}

Individuals' conceptions of their own ability were identified as a source of self efficacy information. Thirteen participants demonstrated a high level of awareness of the relationship between their self-efficacy beliefs and the performance results they achieved, as highlighted in comments such as 'I have a strong belief that I can get the job done. If something is given to me to do, a specific task, then I believe that I can do it more than 100\%. This is the type of person that I am. I never doubt my ability.'
Previous research has indicated that achieving success in challenging tasks provides the strongest information for changing or enhancing beliefs of personal efficacy (Stadjkovic \& Luthans, 1998). An individual's willingness to accept new challenging tasks is related to how they perceive the concept of ability (Bandura, 1988; Dweck \& Elliot (1983) as cited in Bandura (1988)). Individuals who see ability as an acquirable skill that can be continually enhanced adopt learning goals and seek challenging tasks that provide opportunities to expand their competencies, while those who regard ability as a fixed capacity tend to prefer tasks that minimise errors and enable them to demonstrate proficiency at the expense of learning new skills (Bandura, 1988). In this research, five participants who reported a high level of confidence in their problemsolving and learning abilities indicated that they actively sought out new challenging tasks to build their self-efficacy beliefs. They enjoyed generating creative options to solve challenging problems and the immediate feedback regarding their capabilities that a successful problem resolution provided. This learning orientation and concept of ability as an acquirable skill was manifested in comments such as ' $I$ am willing to learn and I have the confidence that I will acquire the capabilities I need to tackle the task successfully.'

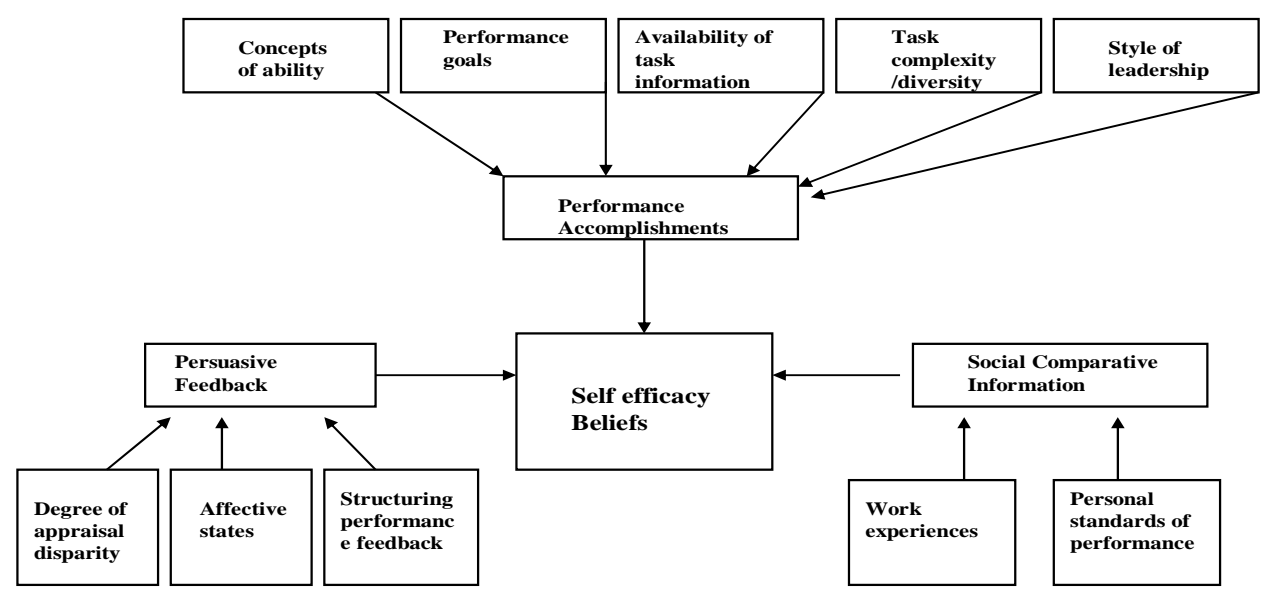

Figure 1: Model of information referents in work environment that contribute to the development of self efficacy beliefs 
According to Bandura (1988), when faced with challenging tasks, individuals who view ability as an acquirable skill take a task-diagnostic focus to determine the cause of the problem and how best to master the challenge. Such individuals are not only better equipped to tackle new challenges, but also to manage everyday life and achieve their performance targets (Bandura, 1997). Bandura's (1997) research shows that individuals tend to avoid tasks they believe exceed their capabilities and instead undertake those they judge themselves capable of handling. Perceptions of general personal efficacy can either facilitate or hinder active engagement in the very tasks that can build efficacy beliefs (Bandura, 1997; Gist, 1987). In this research, participants who viewed ability as an acquirable skill used positive self-talk to strengthen their beliefs that they were capable of taking on challenging tasks: '...if I tell myself I can't, this will build up a barrier to me attacking the task successfully, so I tell myself you have it, now go into the task and do it to the best of your abilities.'

In line with previous research (Bandura, 1997; BouffardBouchard, 1990), participants' self-talk also influenced the effort they expended on a task and the amount of time they dedicated to the task when faced with adversity. Their selftalk contributed to the formation of their efficacy beliefs. This is primarily because of the differing outcomes envisaged: highly efficacious individuals visualised success, while those who judged themselves as inefficacious were more inclined to visualise failure scenarios (Seligman, 1990; Wood \& Bandura, 1989). Optimism was reflected in many comments from participants in the current study similar to the following: '....whatever new task comes before me, I always take it up with the same vigour and the same enthusiasm, and I don't let myself think that it's too difficult for me!'

Many participants in the current study attributed their current beliefs on causal efficacy to childhood experiences, in line with Bandura's (1997) research. Repeated observation enables a child to learn about contingent relations between actions and effects. As children experience success in controlling environment events, they develop a sense of causal efficacy. These early childhood efficacy experiences are central to the development of social and cognitive competence (Bandura, 1997).

\section{Performance goals}

In line with previous research (Bandura, 1988; Locke \& Latham, 1984; Shaw, Saari \& Latham, 1981), twelve participants in this study reported setting specific daily and weekly performance goals, which built their self-efficacy beliefs. For example, a participant stated that ' $I$ want to measure myself against the successes of every day. I want to see the impact of my work'

Goals have a positive effect on performance accomplishments through increasing motivation and selfefficacy (Bandura, 1988). Participants in the current study reported that goals provided them with a sense of purpose and direction, which motivated and energised them to direct their efforts towards goal achievement (Latham \& Lee,
1986; Locke et al., 1981). Current research results indicated that performance goals had increased cognitive and motivational benefits when individuals were personally involved in setting them, when they were linked to specific targets and when individuals received feedback on their performance progress. These factors ensure that successful task experiences result in the strengthening of self-efficacy beliefs (Shea \& Howell, 2000). The impact of feedback is particularly important in formulating self-efficacy beliefs (Bandura, 1988; Bandura \& Cervone, 1983, as cited in Gist, 1987). Previous research has shown that while favourable feedback has a positive effect on self-efficacy beliefs, unfavourable feedback tended to yield negative selfevaluations (Gist, 1987).

Four of the participants in the current study not only set their own performance goals, but also focused on improving their past performance. Previous research findings have shown that individuals who strongly believe in their capabilities set higher goal challenges, while those who doubt their capabilities to achieve success again, lower their goals (Bandura, 1988). While goals help to build people's selfefficacy beliefs, these beliefs in turn influence the goals people set for themselves (Appelbaum, 1996). As is often the case in an organisational context, when employees must deal with pre-assigned goals that are related to productive activity or broader strategic priorities (Appelbaum, 1996), such assigned goals can still stimulate effort and build selfefficacy beliefs provided they are specific and employees understand the business rationale behind them. Assigned goals can also serve to establish normative expectations around which personal goals can evolve (Appelbaum, 1996).

\section{Availability of task information}

Without exception, all participants wanted to know how their actions impacted the success of the organisation. As in previous research (Bandura, 1984, 1997, 1999; Pajares, 2000), this motivated them to persist in the face of challenging obstacles and strengthened their self-efficacy beliefs. For example, a participant commented that 'It is very stimulating to actually physically see how you add value to something, how the whole supply chain process has gained from the problem that you solved. This makes you determined and motivated to even improve on that situation. You feel energised and good about your abilities.'

Participants emphasised that information that was made available to them by their managers when delegating tasks to them influenced whether or not they had confidence in their abilities to succeed or whether they would be plagued by self-doubt. Information regarding specific task attributes, complexity, task environment, expected effort, physical, analytical, and psychological task demands as well as strategies required to influence performance should therefore be strategically and appropriately communicated as they provide the basis for optimal self-efficacy judgments (Appelbaum, 1996).

\section{Task complexity/diversity}

The findings in the study revealed that the successful completion of new and challenging tasks provided strong 
efficacy information and also influenced participants' levels of job satisfaction.

Bandura (1997) noted that the value of performance successes for judging self-efficacy would depend on the perceived difficulty of the task. Succeeding at an easy task provides little efficacy information, while mastery of difficult tasks conveys strong information for raising beliefs in personal capabilities. Individuals make inferences about the complexity and difficulty of the task, not only from the features of the task, but also from the perceived similarity to other activities (Bandura, 1997). Previous research has suggested that full mastery of a complex task is not needed to enhance efficacy beliefs (Stadjkovic \& Luthans, 1998). Rather, even small performance improvements on tasks that are highly complex can produce large increases in selfefficacy. This is more likely to be the case if the individual evaluates personal and situational factors in a way that confirms the perception that they have the necessary capabilities to succeed.

\section{Style of leadership}

All participants in the study reported that their manager's leadership style influenced their self-efficacy beliefs. Specifically, the findings showed that a more empowering style of leadership, in which employees were involved in problem-solving, decision-making and goal-setting, motivated and energised employees to achieve the necessary performance results and created conditions that were more conducive to the development of self-efficacy beliefs. This influence on self-efficacy beliefs was both direct and indirect. The opportunity for participation motivated employees to achieve levels of performance that directly enhanced efficacy beliefs. In addition, participants felt that by enabling employee participation and by delegating challenging tasks, a manager was indirectly communicating a belief in the employee's capabilities: 'When you are asked for your input and your ideas are listened to, you feel that there is confidence in your abilities.'

\section{Persuasive feedback}

The second core theme that emerged from this research, labelled Persuasive Feedback, reflects the perceptions of participants regarding the impact that verbal feedback from managers has on the formation of self-efficacy beliefs.

Seven participants reported that feedback from managers, be it on task performance or personal capabilities, impacted the efficacy beliefs they formed. Positive feedback in particular also had a strong motivational impact, as demonstrated in Bandura's (1997) research. Comments from participants included 'My manager impacts the beliefs I have about myself a great deal' and 'Positive feedback from my manager makes me feel a lot more capable of producing the goods.'

The following personal and situational factors appear to moderate the impact of persuasive feedback on the formation of efficacy beliefs.

\section{Degree of appraisal disparity}

The results of the study support the argument that managerial feedback influences the strength of individuals' self efficacy beliefs but various variables moderate this relationship. Results revealed that the impact of persuasive feedback on self-efficacy beliefs was moderated by the degree of discrepancy between the feedback and the individual's own beliefs about his/her capabilities. Participants discounted feedback that differed markedly from their own efficacy judgments, first cognitively processing the feedback before assigning meaning to it. These results support Nease, Mudgett and Quinones’ (1999) finding that existing perceptions of self-efficacy influenced reactions to feedback and subsequent performance. Both high and low self-efficacy individuals interpret feedback in ways that are protective of their initial self-efficacy perceptions (Nease et al., 1999). Persuasive efficacy attributions thus have their greatest impact on those people who already possess strong self-efficacy beliefs (Bandura, 1986; Chambliss \& Murray, 1979, as cited in Bandura, 1997). When faced with repeated positive feedback, individuals with lower self-efficacy perceptions may begin to judge the feedback as less accurate, in line with their initial efficacy judgements (Nease et al., 1999). Raising unrealistic beliefs of personal capabilities may therefore discredit the persuaders and further undermine an individual's self-efficacy beliefs (Bandura, 1997).

\section{Affective states}

An individual's affective state is another variable that can moderate the relationship between managerial feedback and self efficacy. Mood states can bias attention, affect how events are interpreted and can influence evaluative judgements (Bower, 1981, 1983; Eich, 1995; Isen, 1987; Schwartz \& Clare, 1988: all as cited in Bandura, 1997). The results suggested that participants' affective states appeared to influence the impact that persuasive feedback from managers had on task performance and employee morale. This influence was, however, less than that of the degree of appraisal disparity. It is not clear, however, from these findings whether persuasive feedback in this context directly strengthened efficacy perceptions or merely improved motivational levels.

\section{Structuring of performance feedback}

Bandura (1997) noted that the structuring or framing of performance feedback could either undermine a person's sense of self-efficacy or boost it. The majority of the participants in the current study commented that feedback had the greatest positive impact on their self-efficacy beliefs when it was specific and detailed, and supported by concrete examples. This is supported by Bandura's (1997) recommendation that managers should frame feedback as performance achievements and highlight personal capabilities. Participants in the current study also emphasised that negative feedback conveyed inappropriately can evoke feelings of failure. Bandura (1997) recommended that managers refrain from framing feedback in terms of shortfalls from performance goals as this focus on deficiencies can diminish self-efficacy beliefs. Destructive 
critical feedback undermines self-efficacy beliefs, while constructive developmental feedback often bolsters a sense of personal efficacy (Baron, 1988, as cited in Bandura, 1997); Brief \& Aldag, 2001). Jourden (1991, as cited in Bandura, 1997) corroborated these effects in a study in which people received feedback of organisational attainments either as percentage progress towards a desired standard or as a percentage shortfall. Feedback in terms of performance gains enhanced efficacy beliefs and subsequent performance accomplishments, while feedback focusing on how far individuals still had to go detracted from a sense of personal effort and accomplishment.

Participants indicated a strong desire to have more frequent performance appraisal discussions with their managers. They believed that monthly discussions would help them to stay on track and keep them focused on important tasks. However, the majority of the participants did not ascribe much value to feedback received during the formal performance appraisal. It would appear, from comments made by various participants, that the tendency in these performance discussions is to focus on reaching agreement on the performance ratings, as opposed to qualitative feedback on the performance results that were achieved, and more importantly feedback on how the result was attained. Employees wanted managers to comment on the strategy or method they used to achieve a particular result and how they used or applied specific competencies (skills, knowledge and attitude, behaviour).

\section{Social comparative information}

The third and final core theme that emerged from the study is labelled Social Comparative Information. This theme refers to vicariously derived information that influenced the formation or strengthening of efficacy beliefs. As in other studies this information source appears to have a lesser impact amongst our sample of participants than information derived from performance accomplishments and performance feedback, with efficacy appraisals found to be only partly influenced by vicarious experiences or social comparison with others (Bandura, 1997; Stadjkovic \& Luthans, 1998).

Only three of the participants in the current study reported comparing themselves with others in order to make selfefficacy judgements. As in previous research (Appelbaum, 1996; Bandura, 1997; Brief \& Aldag, 2001), these participants reported that observing others perform similar tasks less successfully made them feel more confident about their own capabilities. For example, one stated that 'I tend to compare myself to an equal who I know I would do their job better.'

Social models provide more than a social standard against which to appraise personal capabilities. They also transmit knowledge, skills and coping strategies to observers (Bandura, 1997; Wood \& Bandura, 1989). Models in the environment model efficacy by word as well as by action (Bandura, 1997). Models who express confidence and determination in the face of difficulties can instil a sense of efficacy and perseverance in others (Zimmerman \& Ringle, 1981, as cited in Bandura, 1997). Social Cognitive Theory provides a body of evidence about how people can turn to proficient models for knowledge, effective strategies, behavioural competencies and socio-cognitive skills (Bandura, 1986; Rosenthal \& Zimmerman, 1978, as cited in Bandura, 1997). Specifically with more complex activities, verbalized thinking skills that guide actions are more informative than modelled actions. Verbal modelling of cognitive skills enhances beliefs of personal efficacy and promotes cognitive skill development (Schunk, 1981; Schunk \& Gunn, 1985; Schunk \& Henson, 1985, all cited in Bandura, 1997). Six participants reported comparing themselves with others in order to learn or improve on their capabilities. These employees selected models in the work environment that possessed competencies to which they aspired: 'I compare myself with others in order to learn from them and get ideas on how to perform certain tasks.'

A few participants also used social comparative information to boost their confidence to experiment with creative work practices. One participant commented: 'When they do something, I sometimes think by myself, but I would have done it this way, or put this system in place to help me'. It appears that seeing someone else use a strategy that has not worked raises the observer's confidence to use a different strategy.

The findings also indicated that an individual's psychological state or mood could create conditions or circumstances, which compel them to compare themselves with others. One respondent stated then when she is feeling down, she would compare herself with someone on an equal level to her, in order to feel better about her own abilities.

The following two factors moderated the influence of efficacy information derived through comparison with others.

\section{Working experience}

In the current study, an individual's years of working experience influenced their susceptibility to vicariously derived information. All of the participants had more than two years working experience and reported a preference for making judgments of personal efficacy on the basis of task experience as opposed to social comparison with others. Six participants reported comparing themselves with others in the work environment when they first started off in their careers, but now that they have gained relevant working experience, successful task experiences are used to inform efficacy judgements. This finding is verified by previous research results, which revealed that individuals who lacked direct knowledge of their own capabilities tend to rely more heavily on vicarious experiences (Takata \& Takata, 1976, as cited in Bandura, 1997).

\section{Personal standards of performance}

Twelve of the interviewees stated that they did not compare their performance or abilities with that of others in the work environment. These employees have specific and clear standards that they use to make judgments about their performance and their capabilities. These standards are either documented in the performance contract, or simply 
exist in the minds of the individuals. Previous research findings suggest that self-modelling may produce a general increase in self-efficacy (Bandura, 1997). Creer and Miklich (1970, as cited in Bandura, 1997) found that observing oneself perform successfully improves targeted performance, thereby facilitating efficacy enhancing processes. It is not clear however whether the observation referred to in this context refers to indirect observation (for example videotaped performances) or real-time observation during the performance of task activities.

\section{Application, recommendations and conclusion}

Previous research has yielded strong empirical evidence on the relationship between work performance and self-efficacy (Bandura, 1997; Brief \& Aldag, 2001; Cervone, 2000; Gist, 1987; Wood \& Bandura, 1989). Perceptions of efficacy influence the goals people set for themselves, the commitment they have to meeting various challenges, how much effort they will expend on tasks, how long they will persevere and how resilient they will be when faced with adverse situations, failures or setbacks (Bandura, 1988, 1997, 1999). Specifically self-efficacy has been found to significantly predict future performance (Bandura, 1997) and to be a better predictor of future performance than past behaviour (Gist, 1987). However, despite the impressive empirical evidence supporting the self-efficacy and work performance relationship, the organisational application of self-efficacy is often neglected.

The current research focused on the formation of selfefficacy beliefs within an organisational context. The authors believe that understanding the formation of selfefficacy beliefs can provide insight into the organisational factors that may encourage or inhibit the formation of efficacy beliefs. This understanding can be used to inform human resource management practices that will develop and strengthen self-efficacy beliefs, which in turn can lead to improved employee performance and ultimately improved organisational performance.

The research findings of the present study suggest areas where actions could be taken to facilitate the strengthening of efficacy beliefs within an organisational context:

1. Research findings suggest that goals are highly effective motivators and efficacy builders. For goals to have both a motivational and cognitive benefit, they should be definite, specific and sufficiently challenging. Performance goals should clearly define the outcome that should be achieved. Goals should be linked to relevant and specific targets, so that there are clear guides for performance and for evaluating how one is doing.

2. The level at which goals are set may also affect employees' motivation and the formation of efficacy beliefs. Success at accomplishing tasks that are sufficiently challenging raises employees' beliefs that they have what it takes to succeed. Managers should, however, ensure that goals are not set too high, as failure can reduce the motivation to continue.
3. Employees could play an active role in setting goals and determining performance targets. If it is an organisational requirement that goals are documented and captured in a performance contract, managers must refrain from drawing up the document on the employee's behalf.

4. Performance appraisals are typically part of the formal performance management process in organisations. The desired outcome of this discussion is performance improvement, yet it appears that employees may not attach value to the feedback they receive during the performance appraisal. Performance feedback, specifically feedback that focuses on personal capabilities that affect performance outcomes is particularly valuable in strengthening beliefs. For performance feedback to have efficacy value it must be specific, supported by concrete examples and positively worded. Ideas should be solicited from the employee on how to improve performance or close any performance gap.

5. In order to facilitate efficacy-enhancing feedback, it is suggested that managers should supplement outcome measures with process measures and behavioural measurements.

6. Guided mastery modelling techniques could be applied to skills training and development practices (Appelbaum, 1996).

7. Information relevant to delegated tasks could be communicated more effectively. It is suggested that managers communicate the strategic importance of the task, how the task impacts other performance outcomes and/or the overall success of the division or organisation. If employees understand the value of their contribution within the broader organisational context they will be more motivated to achieve the required performance results and will thereby set in motion the efficacy enhancing process.

In conclusion this research supports the understanding that the self-efficacy construct is critically important in the management of human behaviour in organisations, given the context within which organisations operate and the resultant demands that are being placed on employees. South African organisations in particular are faced with increased demands to perform more efficiently and effectively in order to compete globally.

Typical organisational responses to global challenges have included downsizing, business process reengineering, total quality management and more extensive use of information technology; largely overlooked are tactics that will enable organisations to utilise employees to their full capacity and upgrade the role that employees can play in meeting competitive demands (Stadjkovic \& Luthans, 1998). The need for employees to take on new and unfamiliar roles and tasks is an initial implication of all such organisational change (Appelbaum, 1996) and these changes require employees who have strong perceptions of their own 
efficacy and who are capable of dealing with adverse situations in the accomplishment of performance goals.

Previous research provides strong support for a significant relationship between self-efficacy and employee performance (Bandura, 1997). The results of the current study reveal that information sources within the organisational environment influence the formation of efficacy beliefs. Specifically successful tasks experiences or performance accomplishments, persuasive feedback from employees' managers and social comparative information derived from colleagues, have a significant influence on the strengthening of efficacy perceptions. It is recommended that future research utilise the model presented in Figure 1 to further investigate the relationships between these information referents and self-efficacy.

Beliefs that both individuals and groups of people hold about their capabilities powerfully influence the way they behave and the performance results they will achieve (Bandura, 1997). An increased focus on the enhancement of employees' self-efficacy beliefs will result in the investment in human resource management practices that will bring about improved employee performance, and ultimately improved organisational performance.

\section{References}

Appelbaum, S. 1996. 'Self-efficacy as a mediator of goal setting and performance: Some human resources applications', Journal of Managerial Psychology, 11: 33-48.

Ballantine, K. \& Nunns, C.G. 1998. 'The moderating effect of supervisory support on the self-efficacy workperformance relationship', South African Journal of Psychology, 28(3): 164-174.

Bandura, A. 1977. Social learning theory. Engelwood Cliffs NJ: Prentice Hall.

Bandura, A. 1984. 'Recycling misconceptions of perceived self-efficacy', Cognitive Therapy and Research, 8: 231-255.

Bandura, A. 1986. Social foundations of thought and action: A social cognitive theory. Englewood Cliffs NJ: Prentice Hall.

Bandura, A. 1988. 'Organisational applications of social cognitive theory', Australian Journal of Management, 13(2): 275-302.

Bandura, A. 1991. 'Self-efficacy mechanism in psychological activation and health promoting behaviour'. In Madden, J. (Ed.). Neurology of learning emotion and affect. New York: Raven Press.

Bandura, A. 1997. Self-efficacy: The exercise of control. New York: Freeman.

Bandura, A. 1999. Self-efficacy in changing societies. New York: Cambridge University Press.
Bouffard-Bouchard, T. 1990. 'Influence of self-efficacy on performance in a cognitive task', Journal of Applied Psychology, 130(3): 353-364.

Brief, A.P. \& Aldag, R.J. 2001. 'The 'self' in work organisations: A conceptual review', Academy of Management, 6: 75-88.

Cervone, D. 2000. 'Thinking about self-efficacy: Going beyond traditional motivational and behavioural approaches', Organisational Dynamics, 26(4): 62-78.

Early, P.C. \& Gibson, C.B. 1999. 'How did I do?' versus 'How did we do?', Journal of Cross-Cultural Psychology, 30(5): $594-620$.

Gist, M.E. 1987. 'Self-efficacy: Implications for organisational behaviour and human resource management', Academy of Management Review, 12(3): 472 - 485.

Gist, M.E. \& Mitchell, T.R. 1992. 'Self-efficacy: A theoretical analysis of its determinants and malleability', Academy of Management Review, 17(2): 183-211.

Harrison, A.W. \& Rainer, J.F. 1997. 'Testing the selfefficacy performance linkage of social cognitive theory', Journal of Social Psychology, 137(1): 79-91.

Kvale, S. 1983. 'The qualitative research interview: A phenomenological and hermeneutical mode of understanding', Journal of Phenomenological Psychology, 14(2): 171-196

Latham, G.P. \& Lee, T.W. 1986. 'Goal setting'. In Locke, E. A. (Ed.). Generalizing from laboratory to field settings. Lexington, M.A.: Lexington Books

Locke, E.A. \& Latham. G.P. 1984. Goal setting: A motivational technique that works. Englewood Cliffs NJ: Prentice-Hall.

Locke, E.A. \& Latham. G.P. 1990. A theory of goal setting and task performance. Englewood Cliffs, New Jersey: Prentice Hall.

Locke, E.A., Shaw, K.N., Saari, L.M. \& Latham, G.P. 1981. 'Goal setting and task performance 1969 - 1980', Psychological Bulletin, 90: 125-152.

Maehr, M. \& Pintrich, P.R. 2000. Advances in motivation and achievements. [online] URL:

http://www.Emory.Edu/EDUCATION/mtp/effchapter html.

Maykut, P. \& Morehouse, R. 1994. Beginning qualitative research. London: The Flamer Press.

McCracken, G. 1988. The long interview. Ontario, Canada: Gage Publications, Inc.

Miles, M.B. \& Huberman, A. M. 1994. Qualitative data analysis. California: Sage. 
Nease, A.A., Mudgett, B.O. \& Quinones, M.A. 1999. 'Relationship among feedback sign, self-efficacy and acceptance of performance feedback', Journal of Applied Psychology, 84(5): 806-814.

Pajares, F. 2000. Current directions in self-efficacy research. In Maehr, M. \& Pintrich, P.R. (Eds.). Advances in motivation and achievements. [online] URL: http://www.Emory.Edu/EDUCATION/mtp/effchapter.html.

Schamberger, M.M. 1997. 'Elements of quality in a qualitative research interview', South African Archives Journal, 39: 25-35

Seligman, M.E. 1990. Learned optimism. New York: Pocket Books.

Shea, C.M. \& Howell, J.M. 2000. 'Efficacy-performance spirals: An empirical test', Journal of Management, 26(4): 791-812.

Stadjkovic, A.D. \& Luthans, F. 1998. 'Social cognitive theory and self-efficacy: Going beyond traditional motivational and behavioural approaches', Organisational Dynamics, 26(4): 62-78.

Sully De Luque, M.F. 2000. 'The impact of culture on feedback seeking behaviour: An integrated model and propositions', Academy of Management Review, 25(4): 829850.

Wood, R. \& Bandura, A. 1989. 'Social cognitive theory of organisational management', Academy of Management Review, 14(3): 351-384. 